Atıf için / For Citation: Y. Güler, "CMS HF dedektöründe kullanılan fiberlerin radyasyondan gördüğ̈̈ zararı görüntüleme sistemi”, Süleyman Demirel Üniversitesi Fen Edebiyat Fakültesi Fen Dergisi, 15(2), 307-318, 2020.

\title{
CMS HF Dedektöründe Kullanılan Fiberlerin Radyasyondan Gördüğü Zararı Görüntüleme Sistemi
}

\author{
Yalçın GÜLER ${ }^{* 1}$ \\ ${ }^{1}$ Çukurova Üniversitesi, Fen Bilimleri Enstitüsü, 01330, Adana, Türkiye \\ *yazışılan yazar e-posta: yalcin.guler@cern.ch
}

(Alınıs / Received: 05.10.2020, Kabul / Accepted: 13.11.2020, Yaylmlanma / Published: 29.11.2020)

Özet: İleri Hadron (HF) dedektörü, Compact Muon Solenoid (CMS) deneyinin her iki yanında bulunup, CMS'nin çok ileri bölgedeki pseudorapidite $(3.0<|\eta|<5.0)$ aralığını kapsar. Her bir HF modülü, demir soğurucuların uzunluğu boyunca ışın demeti eksenine paralel uzanan kuvars liflerinden yapılmıştır. HF, ışın eksenine yakın olduğu için yüksek düzeyde radyasyona maruz kalır. Ve yüksek radyasyon etkisi nedeniyle, kuvars fiberler zamanla bozulmaya başlar. Bu radyasyon etkisini belirlemek için HF detektörüne bazı özel fiberler yerleştirilmiştir. Radyasyonun neden olduğu hasarı izlemek için toplam 56 fiber kanalı kullanılmıştır. Bu çalışma, HF'nin radyasyon hasarının izlenmesi için 2010 yılı çalışma döneminde alınan yerel lazer veriler kullanılarak yapılmıştır. Belirli bir pseudorapidite ve azimutal açıda RadDam kanallarında önemli bir radyasyon hasarı gözlenmemiştir.

Anahtar kelimeler: Radyasyon hasarı, HF, CMS, BHÇ, Fiber, CERN

\section{Radiation Damage Monitoring for The CMS HF Detector}

\begin{abstract}
Hadronic Forward (HF) detector is located on both sides of the CMS experiment and it covers the very forward angles of CMS, in the pseudorapidity range $(3.0<|\eta|<5.0)$. Each HF module is made of quartz fibers running parallel to the beam axis along the length of the iron absorbers. Since HF is close to the beam axis, it is exposed to high levels of radiation. And due to the high radiation effect, quartz fibers begin to deteriorate over time. Some special fibers were placed in the HF detector to determine this radiation effect. A total of 56 sampling fibers are used to monitor the damage caused by radiation. This study is performed using the local laser data which was collected in 2010 run period for monitoring of radiation damage of HF. No significant radDam is observed in channels at a given pseudorapidity and azimuthal angle.
\end{abstract}

Key words: Radiation damage, HF, CMS, LHC, Fiber, CERN 


\section{Giriș}

Parçacık Fiziği, maddenin en küçük boyutta en temel seviyede nelerden yapılmış olduğunu ele alır. Bu yapının anlaşılması için bilim insanları Standart Model (SM) adında bir kuram ortaya atmışlardır [1]. SM'ye göre evrendeki bütün maddeler kuark ve lepton olarak adlandırılan noktasal parçacıklar ile bozon adı verilen ara parçacıklardan oluşmuştur. Maddeyi oluşturan ve aralarındaki ilişkiyi açıklayabilen SM kuramı, yapılan deneyler sonucunda birçok soruya cevap verebilmektedir, fakat onun da cevaplayamadığı bir takım sorular vardır. Bu nedenle bilim insanları SM ötesi yeni kuramlara yönelmişlerdir. Bu araştırmaları fizikçiler CERN (Avrupa Nükleer Araştırma Merkezi)'de yürütmektedirler. 1989'da yerin 100 metre altında 27 km'lik tünel içine inşa edilen Büyük Elektron-Pozitron çarpıştırıcısı (LEP) sökülerek yerine, 2001 yılından itibaren Büyük Hadron Çarpıştırıcısı (BHÇ), hadronları çarpıştırmak üzere yerleştirilmiştir.

BHÇ’de protonlar ve iyonlar daha önce ulaşılamamış kütle merkezi enerjisi ve 1şıklılıkta çarpıştırılmaktadır. BHÇ üzerinde dört büyük deney yer alır [2-5]. CMS deneyi bunlardan birisidir. BHÇ’nin sağlamış olduğu yüksek 1şıklılık çarpışmaları, dedektörün alt bölümlerinin yüksek oranda radyasyona maruz kalmasına neden olur. $\mathrm{Bu}$ radyasyon etkisine maruz kalan bölümlerinden birisi de CMS'nin bir alt dedektörü olan HF kalorimetresidir. HF ileri bölge jetlerinin ve kayıp dik enerjinin ölçümünde önemli rol oynamaktadır.

\section{Materyal ve Metot}

\section{1 İleri Hadron Kalorimetrenin Yapısı}

Şekil 1'de yan kesiti verilen ileri bölge kalorimetre, dış yarıçap1 $130 \mathrm{~cm}$, iç yarıçap1 $12.5 \mathrm{~cm}$ (1şık demeti borusu için ayrılan boşluk) ve uzunluğu $1.65 \mathrm{~cm}\left(\approx 10 \lambda_{\mathrm{I}}\right)$ olan çelik silindirik yapılıdır. Her bir HF modülünün soğurucu ağırlığı 108 ton olup açısal olarak 20 derece olarak bölünmüş çelik dilimlerin iki yarım silindir şeklinde birleştirilmesiyle oluşur. HF kalorimetreleri, etkileşim noktasının her iki tarafında 18 'er olmak üzere otuz-altı dilimden meydana gelir [5-9]. Her soğurucu dilimde yatay ve dikey olarak $5 \mathrm{~mm}$ olan boylamasına boşluklara yerleştirilen kuvars fiberler vardır. Fiberler, $600 \mu \mathrm{m}$ çaplı birleşik silisyum çekirdek ile $630 \mu \mathrm{m}$ sert polimer kaplama ve $800 \mu \mathrm{m}$ olan koruyucu akrilat kılıftan oluşur. Fiberlerin yarısı soğurucunun tam derinliğinde yer alırken diğer yarısı ise dedektörün ön yüzünden $22 \mathrm{~cm}$ derinlikte başlar. $\mathrm{Bu}$ farklı fiberler ayrı ayrı okunur. $\mathrm{Bu}$ düzenleme, uzun ve kısa fiberlerde sinyal oluşturan hadron, duşlarından ilk 22 cm'lik kısımda enerjilerinin büyük kısmını depolayan elektron, pozitron ve fotonlar tarafindan üretilen elektromanyetik duşun ayırt edilmesini, mümkün hale getirir. Uzun fiberler $(L)$ toplam enerjiyi ve kısa fiberler $(S)$ ise çeliğin yüzeyinden $22 \mathrm{~cm}$ 'den sonra depolanan enerjiyi ölçmek için kullanılır. 


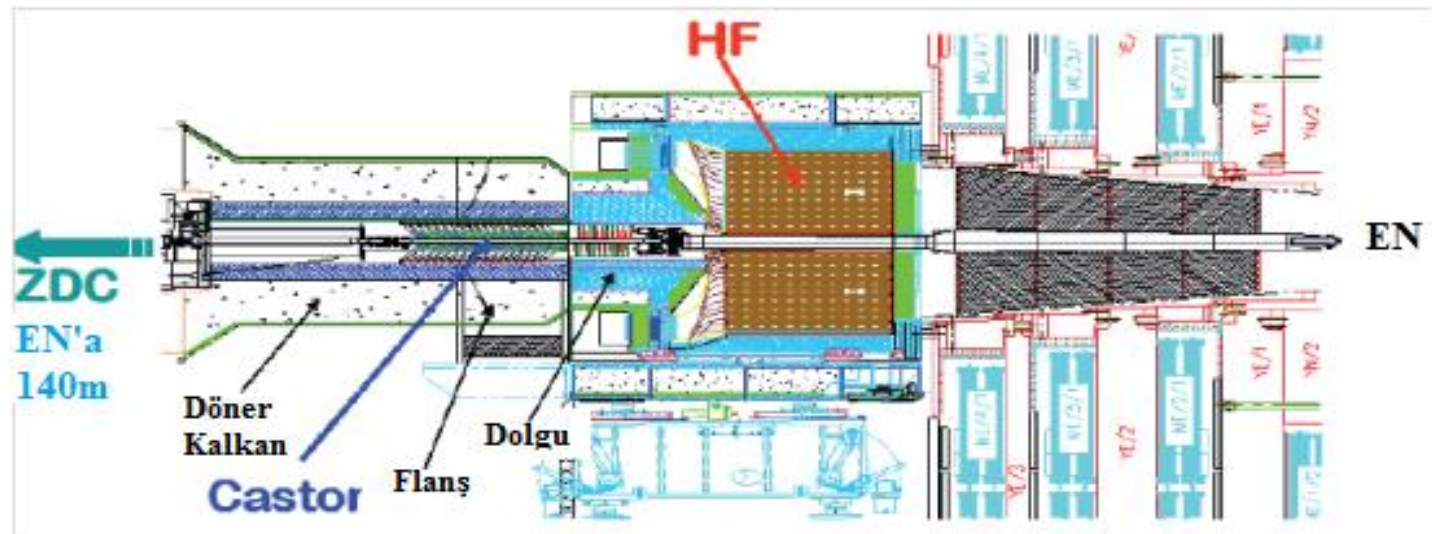

Şekil 1. CMS de etkileşim noktasının bir tarafındaki ileri bölge: $3<|\eta|<5$ pseudorapditiy aralığını kapsayan kuvars kalorimetre HF [5].

\subsection{HF'de Radyasyon Zararını Görüntüleme Sistemi}

HF'de Radyasyon Zararını Görüntüleme Sistemi (RadDam) dedektörün radyasyondan göreceği hasarı çevrimiçi izlemek üzere tasarlanmıştır [10]. Dedektörün farklı bölümleri farklı radyasyona maruz kalacağından, dedektörün farklı kulelerine toplam 56 tane RadDam fiberi yerleştirilmiştir. Sistemin çalışma prensibi dedektörün giriş kısmından yansıyan ışık atımının dedektörün bitiminden yansıyan ışık atımıyla karşılaştırılmasına dayanmaktadır.

Radyasyonun fiberler üzerindeki etkisini incelemek için kullanılan sistem Şekil 2'de gösterilmektedir. Sistemde 1şık kaynağ1 olarak $337 \mathrm{~nm}$ dalga boyunda 1şık atımları üreten bir nitrojen lazer kullanılır. Lazer ışığının dalga boyu fiberde en çok soğurulan dalga boyu bölgesine denk düştügü için geri besleme konektörüne yerleştirilmiş $2 \mathrm{~cm}$ uzunluğundaki sintilasyon fiberi sayesinde mavi bölgeye $(440 \mathrm{~nm})$ doğru kaymasi sağlanmıştır. Bu 1şık her bir HF için 4 kamaya dağıtılır. Her bir kama içerisinde değişik bölgeleri kapsayacak şekilde yedi kuleye bu örnekleme fiberleri yerleştirilmiştir. Her bir fiber yerleştirilen kuleye ait PhotoMultiplier Tube (PMT) tarafindan okunur. Radyasyondan kaynaklanan hasarı çevrimiçi belirlemek için toplam 56 örnekleme fiberi kullanılmıştır [11-16].

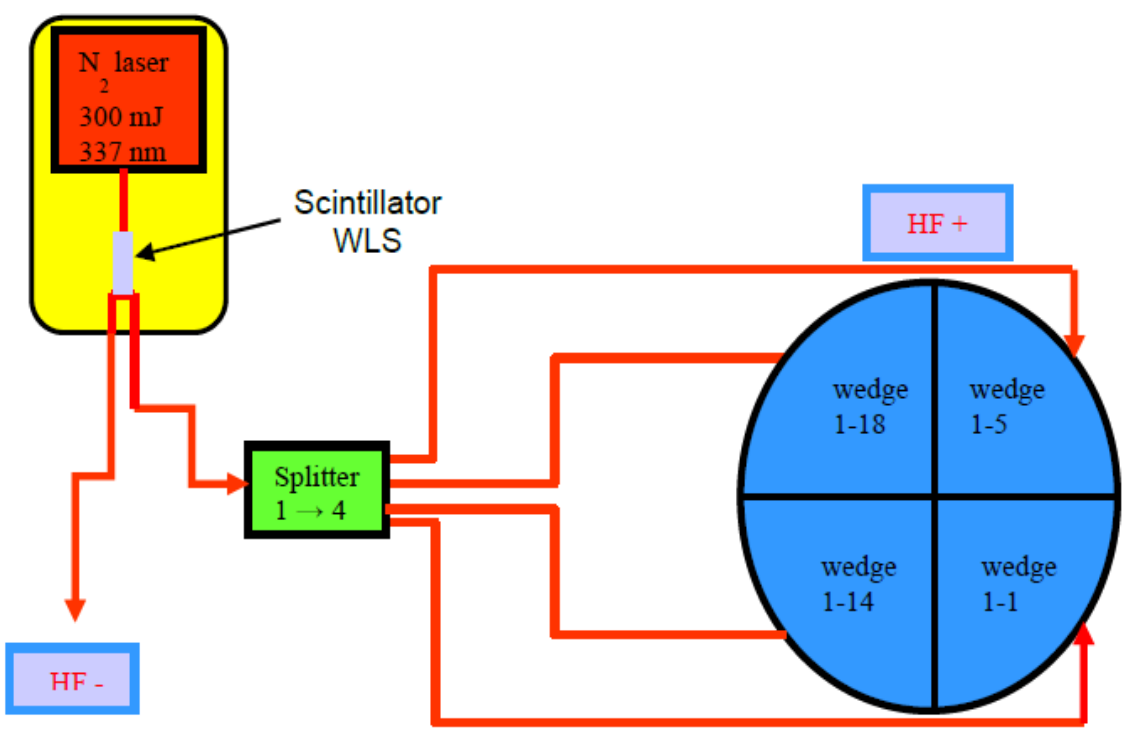


Şekil 2. RadDam Sistemi. Lazerden gelen ışık $440 \mathrm{~nm}$ dalga boyuna kaydırılarak bir dağıtıcı aracılığıyla dört dilime dağıtılır.

\subsection{RadDam Sisteminin Çalışma Prensibi}

Lazerden gelen fiber ile kule içerisine yerleştiren fiberin birleşim bölgesinde Şekil 3'de gösterildiği gibi bir miktar hava boşluğu bulunmaktadır. Bu sayede lazerden gönderilen 1şığın bir kısmı kuledeki fiberin ön yüzünden yansımaya uğrar. Kule içerisindeki fibere iletilen 1şık bu fiber üzerinde ilerler ve fiberin sonunda tekrar hava ile karşılaştığında buradan da bir yansıma yapar. Birinci yansımanın olduğu bölge dedektör dışında olduğundan bu yansımanın radyasyondan pek etkilenmesi beklenmemektedir. Fakat ikinci yansıma kuledeki fiberin içinde iletildiğinden bu yansımanın genliğinin radyasyondan dolayı azalması beklenir. Dolayısıyla bu iki yansımanın oranı, fiberlerin radyasyondan ne kadar etkilendiğini göstermektedir $[17,18]$. Yansıyan iki sinyal bir başka fiber aracılığıyla ölçülmek üzere PMT'ye iletilir. İkinci sinyal kule içerisindeki fiberi iki kez kat ettiği için foto-çoğaltıcı tüp tarafından 25 ns sonra algılanır. CMS'nin okuma sistemi 25 ns'lik ardışı 10 zaman dilimine dayanır. Bu nedenle bu iki sinyal Şekil 3'teki gibi birbirine komşu iki zaman diliminde yer alır. Dedektörün uzun yıllar çalışması sonucunda radyasyon etkisine maruz kalacak olan fiber optik kablolar zamanla kararacak ve daha az ışı̆̆ı geri yansıtabilecektir. Işığın azalması dedektörün zamanla radyasyondan ne kadar etkileneceğini gösterecektir. RadDam fiberlerinin HF içerisinde hangi kulelere yerleştirildiği Şekil 4'te gösterilmektedir.

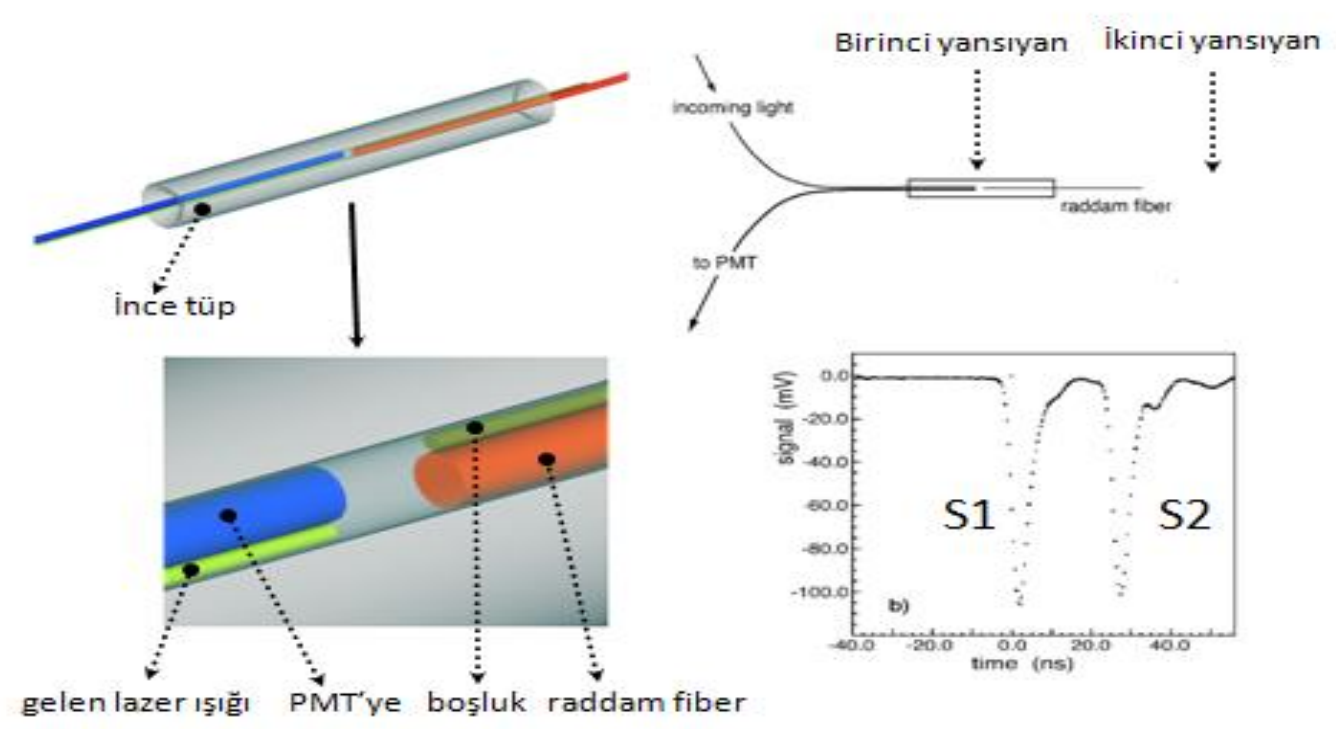

Şekil 3. Lazer sinyalinin, kuledeki fibere iletimi ve yansıyan ışı̆̆ın PMT’ye dönüşünü bir cam tüp içerisinde nasıl yerleştirildiğinin temsili resmi, birinci ve ikinci yansıyan sinyallerin aralarındaki zaman farkı ve sinyalin şekli. 

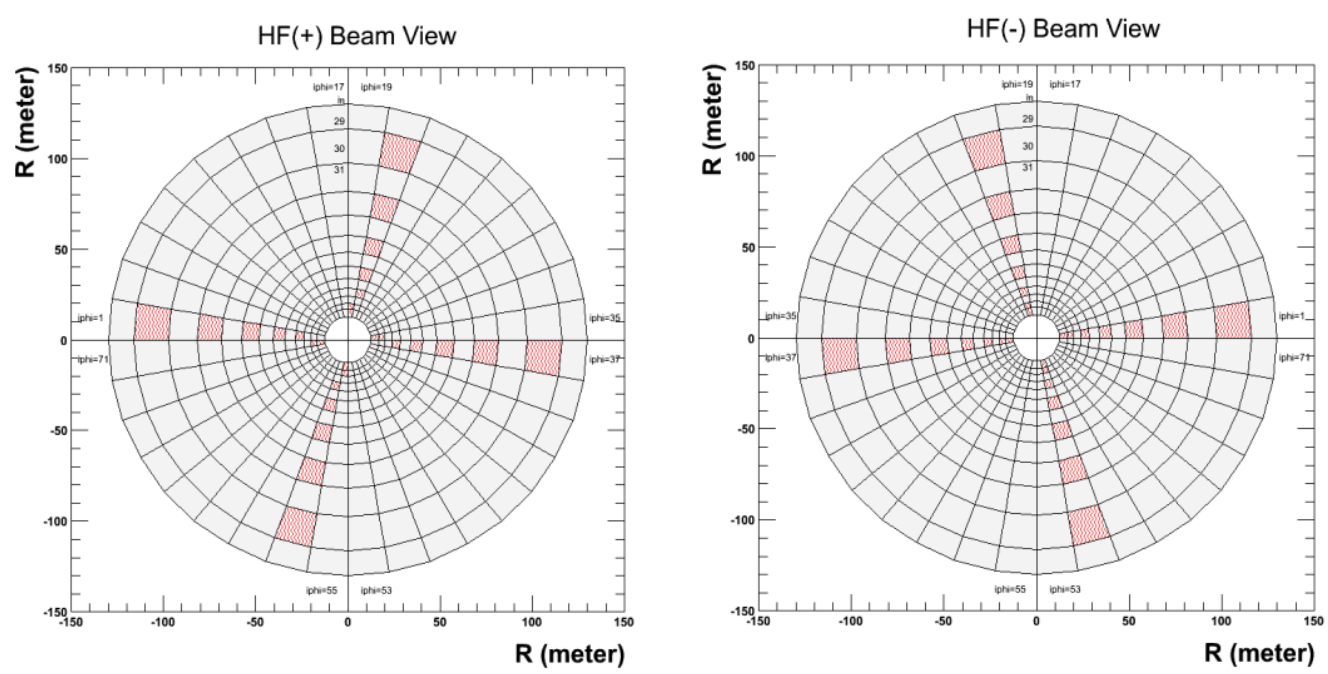

Şekil 4. RadDam fiberlerin yerleri kırmızı kutular ile gösterilmiştir.

Bir önceki bölümde de belirtildiği gibi sistem art arda gelen, iki sinyalin oranlarının karşılaştırılması temeline dayanmaktadır. Bu bölümde 2010 yılında alınan lokal verilerin analizleri sirasında kullanılan metot hakkında bilgi verilecektir.

İlk olarak, alınan veride fiberlerden yansıyan 1şıktan elde edilen sinyallerin, hangi zaman dilimlerinde bulunduğunun anlaşılması gerekir. Şekil 5'teki dağılımlar, sadece iki kanal için, birinci ve ikinci yansıyan sinyallerin hangi zaman dilimlerine yayılmış olduklarını göstermektedir.

\subsection{Olay Seçimi}

Şekil 5 a'da görüleceği gibi $\mathrm{HF}(+)$ için birinci ve ikinci yansıyan sinyallerin çoğunlukla 3. ve 4. zaman diliminde (ZD) ve HF(-) içinse çoğunlukla 4. ve 5. ZD'de olduğu Şekil 5 b'de görülmektedir. Şekil 5 'te görülebileceği gibi sinyaller, çeşitli nedenlerle olmas1 gereken ZD'lerinden komşu ZD'lerine kayarak sinyali paylaşabilmektedirler. Oranın doğru bir şekilde hesaplanabilmesi için sinyallerin iki zaman diliminde olduğu olayların seçilmesi gerekir.
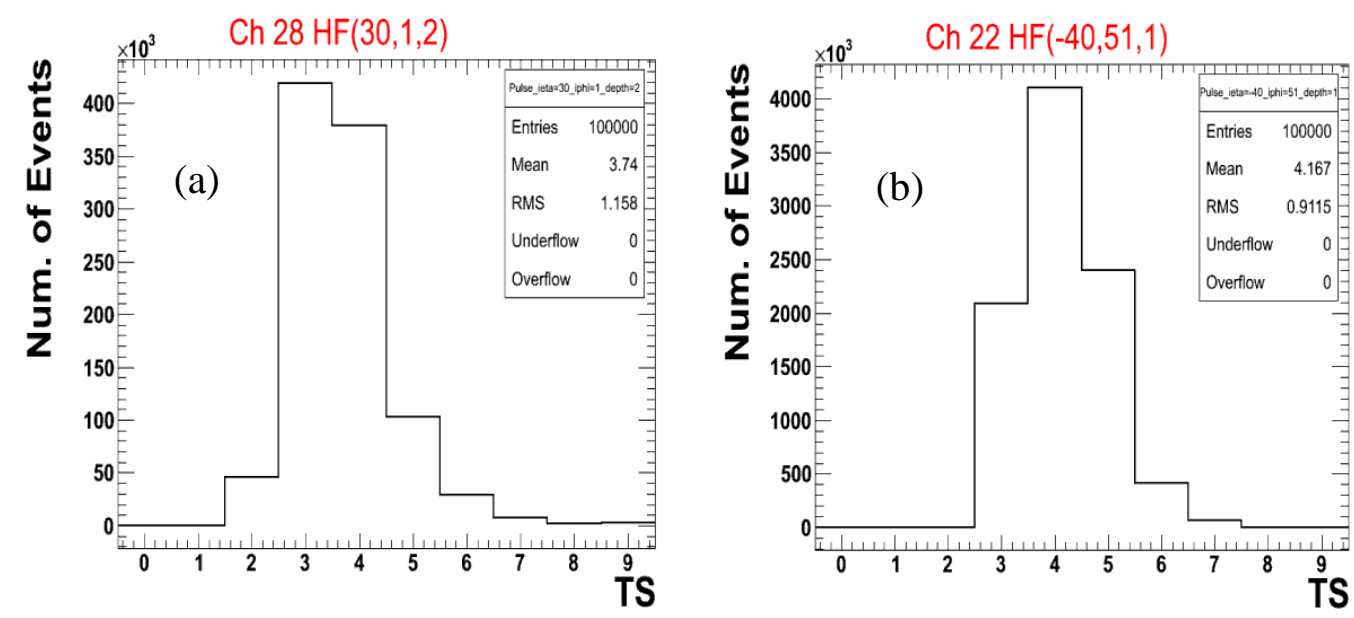

Şekil 5. a) HF (+) için birinci ve ikinci yansıyan sinyalin 3. ve 4. zaman dilimlerinde, b) $H F(-)$ için 4 . ve 5. zaman dilimlerinde olduğunu gösteren dağılımlar. 
Bu çalışmada sinyallerin iki zaman diliminde yer aldığı olayları belirlemek için iki seçim koşulu uygulanmıştır. İlk sinyal $(S 1)$ ve ikinci sinyalin $(S 2)$ taşıdığı yükün 5 fC'tan büyük olması, ilk seçme kriteri olarak belirlenmiştir. Bu koşul, sinyalin dedektörden kaynaklanan gürültü değerlerinin üstünde olmasını ve lazerden kaynaklanabilecek bir takım sorunların (örneğin sinyalin dalgalanması veya sinyallerin zamana göre kayması gibi) dışlanmasını sağlamak için gerekmektedir. Şekil 6'da sırasıyla $\mathrm{S} 1$ ve S2 dağılımları görülmektedir. Bu dağılımda $x$ ekseni sinyalin taşıdığ yükü, $y$ ekseni ise olay sayısını göstermektedir. Bu dağılımdan $5 \mathrm{fC}$ 'tan aşağısının gürültü olduğu görülmektedir. Bu dağılım göz önünde bulundurularak birinci olay seçim şartı şöyle uygulanmıştır:

$$
T S[J]>5 f C \text { ve } T S[J+1]>5 f C
$$

Gürültüler elimine edildikten sonra, sinyalin iki zaman diliminde olduğu olayları seçmek gerekir. Bunun için, sinyalleri içeren dört zaman dilimindeki yüklerin $\% 95$ 'nin iki zaman diliminden gelmesi istenir. Bunu uygulamak için aşağıdaki eşitlikten yararlanılmıştır. Örneğin, $H F(+)$ için 3. ve 4. zaman dilimlerindeki yük miktarının (2Q), 2., 3. , 4. ve 5. zaman dilimlerindeki yük miktarına (4Q) oranına bakılmıştır. Denklem 2 kullanılarak seçilen olaylar Şekil 7'deki sağ taraftaki dağılımı oluşturmaktadır. Bu seçim şartı sinyallerin olması gereken iki zaman diliminde olmayan olayları elimine etmek için uygulanmıştır. Bu iki olay seçim sonrasında toplam verinin \%20-30 kalmıştır.

$$
\frac{T S[J]+T S[J+1]}{T S[J-1]+T S[J]+T S[J+1]+T S[J+2]}>0.95
$$
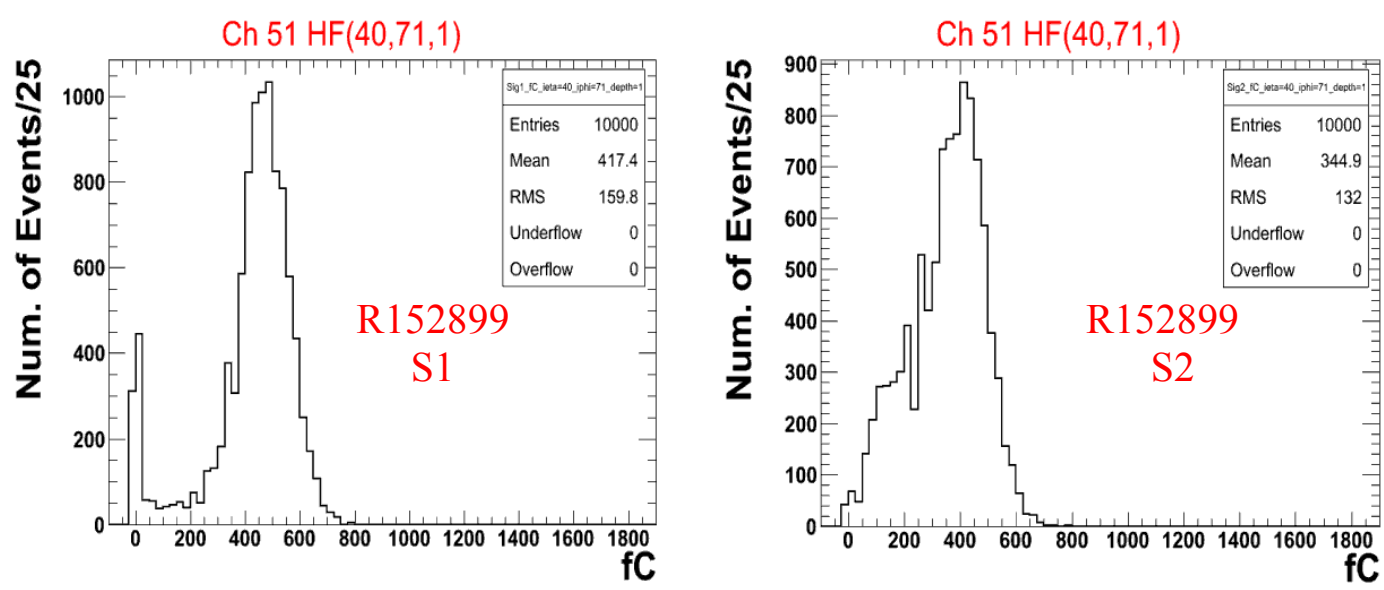

Şekil 6. Birinci ve ikinci yansıyan sinyallerin yük dağılımları. 

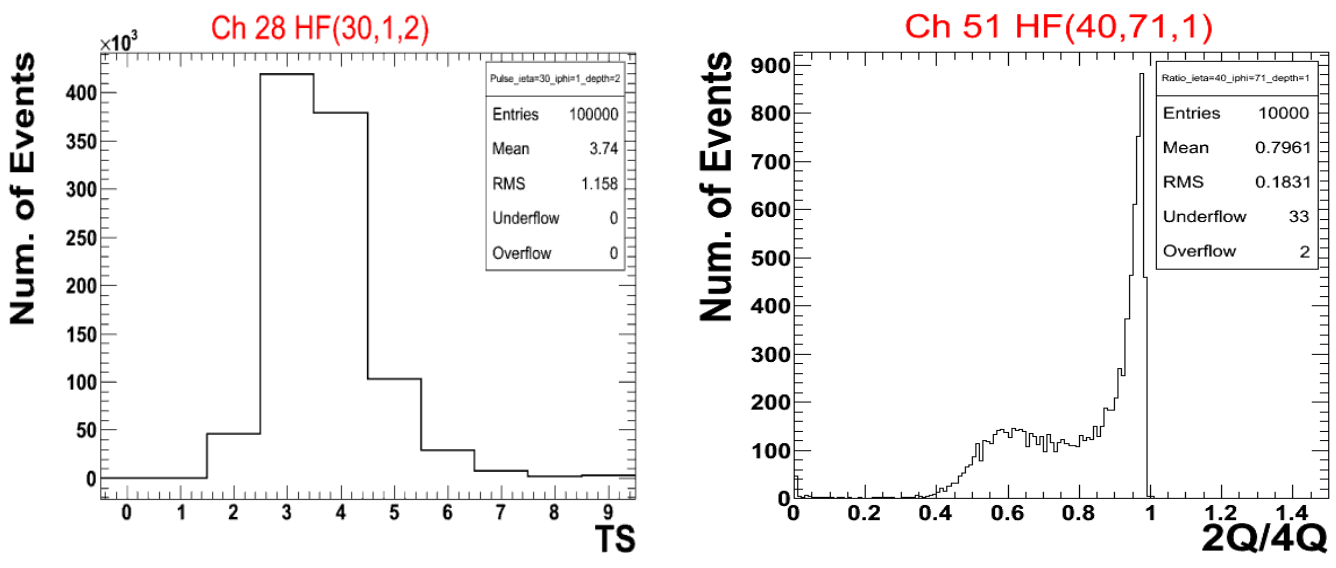

Şekil 7. Olay seçimine karar vermek için kullanılan dağılımlar.

\section{Bulgular}

Radyasyon hasarını gözlemlemek üzere tasarlanmış 56 kanaldan alınan veriye, yukarıda açıklanan olay seçim şartları uygulanmıştır. Birkaç sorunlu kanal hariç, diğer kanalların sinyal dağılımı, Şekil 8 a ve b'de gösterilen 51. kanalın dağılımına benzer olduğu gözlenmiştir. Her bir kanal için birinci ve ikinci yansıyan sinyallerin yük dağılımlarının ortalamasının aynı olmadığı Şekil 9 a ve b'de görülmektedir. Bu bilinen bir davranıştır çünkü her kanalın aynı hassasiyette olmadığı bilinmektedir. Önemli olan sinyal genliğinin analiz edilebilir seviyede olmasıdır. Sabit dağılım aralığı belirlemek bazı kanallarda istatistiksel hatanın artmasına neden olacağı için her kanaldan gelen veriye uygun dağılım aralığı seçilmesi gerekir. Dağılımlar oluşturulurken dikkat edilmesi gereken önemli bir nokta, belirlenen aralığın aritmetik ortalamayı değiştirmeyecek şekilde olmasıdır.
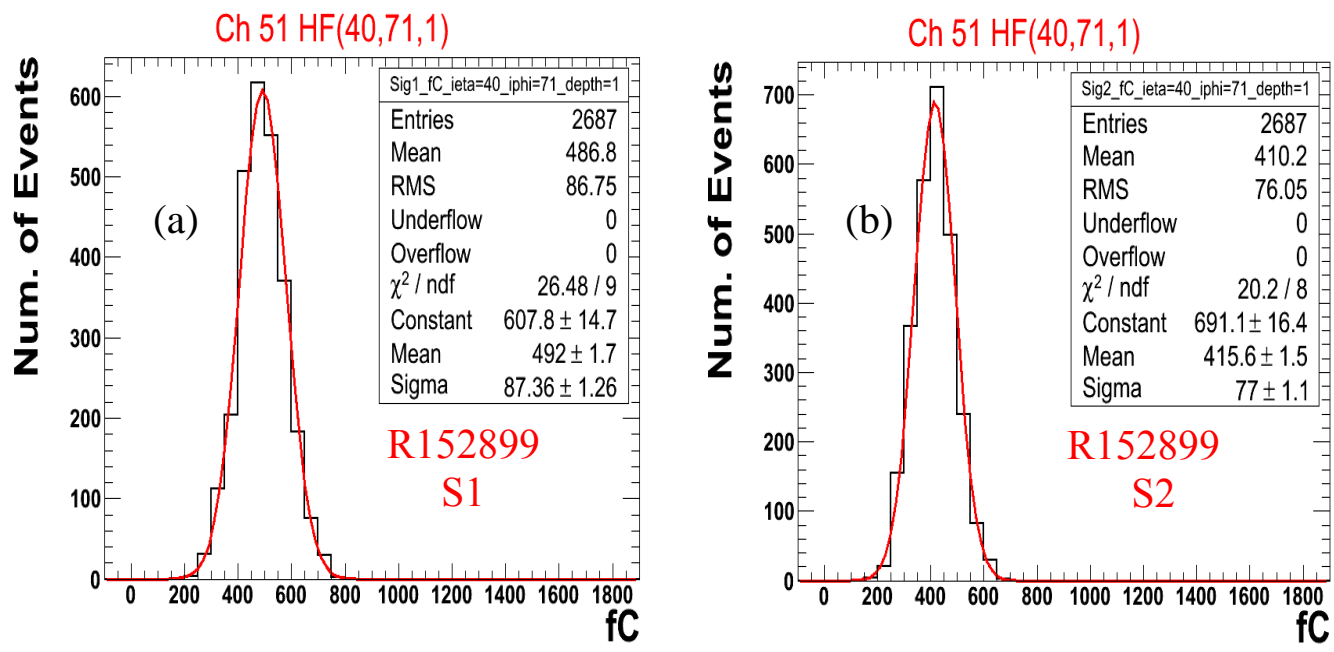

Şekil 8. Birinci ve ikinci yansıyan sinyal dağılımların Gauss fonksiyonuna uydurulmuştur. 

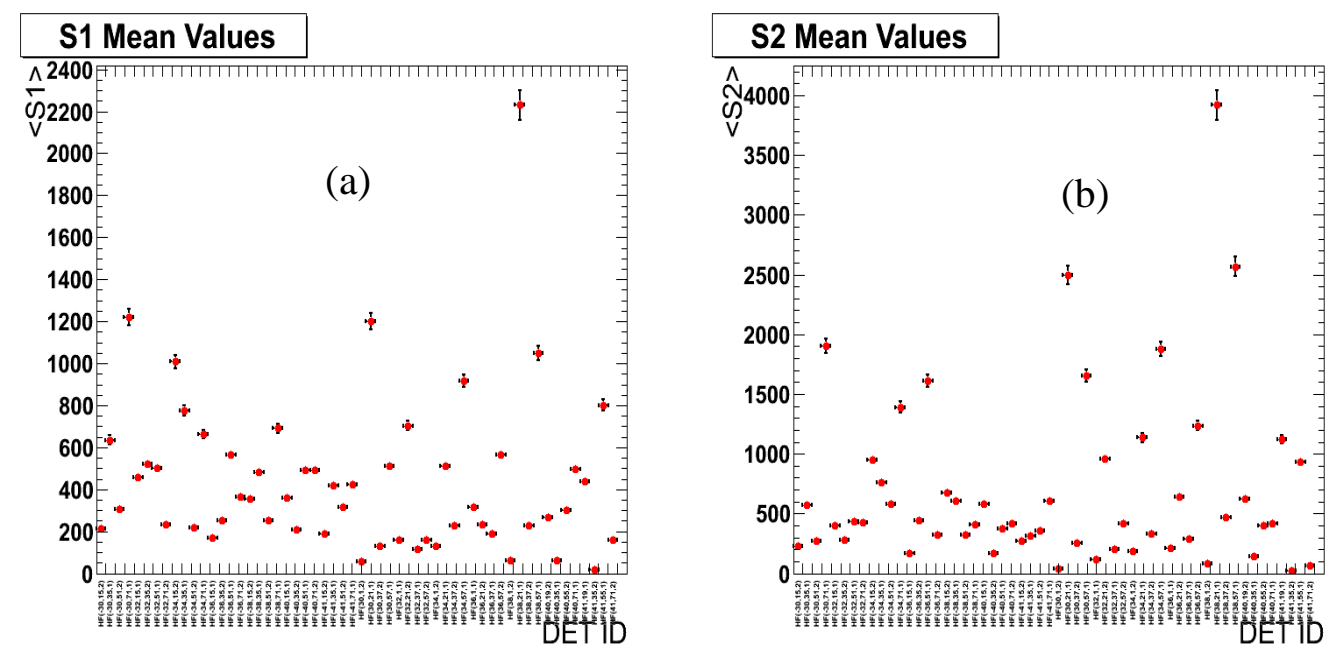

Şekil 9. Her bir kanalın birinci (a) ve ikinci (b) sinyallerinin ortalama değerleri.

Bu çalışmada hata kaynakları, yöntemden ve sistemden kaynaklanan hatalar olarak belirlenmiştir.

\subsection{Yöntemden Kaynaklanan Hata}

Yöntemdeki hatayı belirlemek için farklı zamanlarda alınan verilerin karşılaştırılması gerekmektedir. Böylece veri değişse bile yöntemin kararlı olup olmadığı belirlenmiş olur. Bulunan sonuçların birbirine yakın olması istenilen durumdur. Farklı zamanlarda alınan iki veri seti yukarıda anlatılan metodla ayrı ayrı analiz edilmiş ve her bir kanaldan alınan sonuçlar, diğer verideki aynı kanala ait sonuç ile Denklem 3 kullanılarak oranlanmıştır. Elde edilen bu değerler ile Şekil 10'daki dağılımlar oluşturulmuştur. Bu dağılımın ortalama değeri yöntemin hata payını vermektedir bu da yaklaşık \%1 olarak belirlenmiştir.

$$
\frac{\Delta}{\text { mean }}=\frac{\left|R(t)_{a}-R(t)_{b}\right|}{0.5 \times\left[R(t)_{a}+R(t)_{b}\right]}
$$
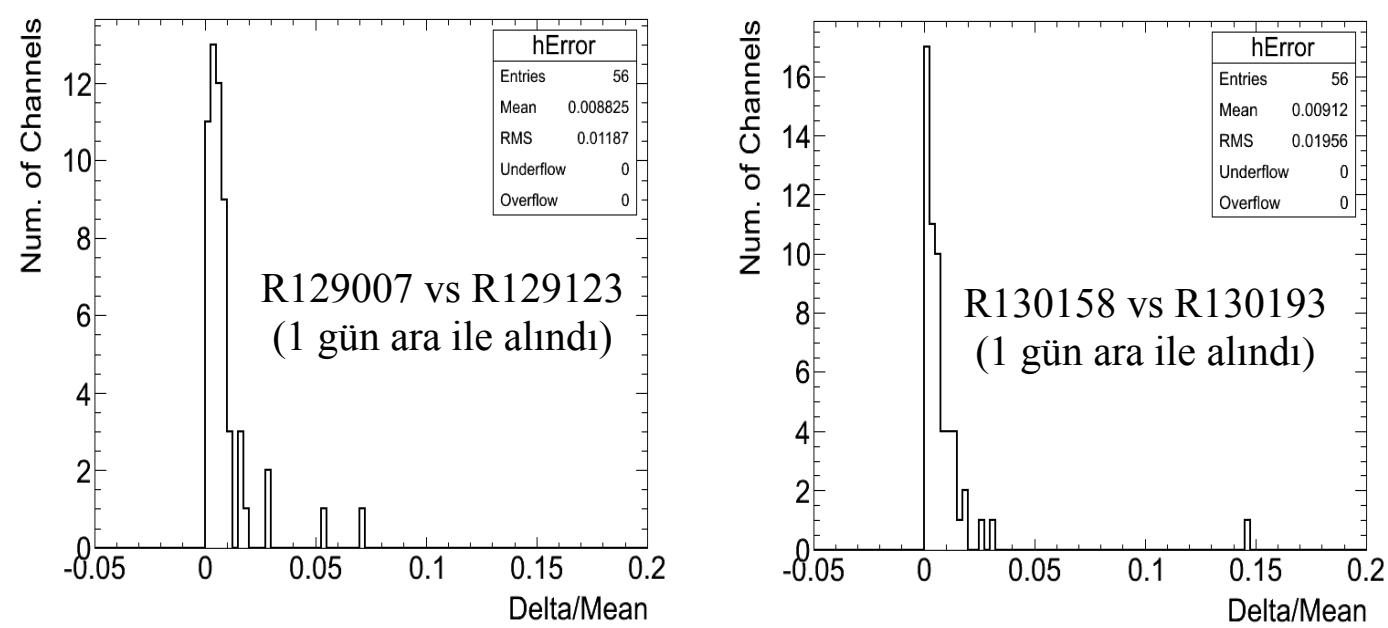

Şekil 10. Birer gün ara ile alınmış veri setleri kullanılarak, belirlenen hata oranları. 


\subsection{Sistemden Kaynaklanan Hata}

Herhangi bir QIE kartı içinde, verinin doğru parçalara ayrılmamasından dolayı oluşan hata oranı \%2'dir [19]. Verinin QIE kartları arasındaki paylaşımından oluşan hata oranı $\% 2.5$ 'dir.

Farklı kaynaklardan gelen katkıyı, hataların karelerinin toplamının karekökünü alarak hesaplanırsa; hata oranının \%3.35 olduğu elde edilir.

$\mathrm{Bu}$ bölümde sistemden alınan veriyi, analiz yapmaya hazır hale getirmek için uygulanan olay seçimi ve farklı davranış gösteren kanallardaki hataların belirlenmesine yönelik yapılan çalışmalar anlatıldı.

\subsection{Radyasyon Etkisi}

Şekil 11'de görülen her bir nokta bir RadDam kanalına ait birinci yansıyan sinyal dağılımının ortalama değerinin bir başlangıç (referans) verisine göre tüm alınan verilerle karşılaştırılmasını gösterir. Şekil 12'de ise benzer şekilde ikinci sinyal gösterilmektedir.

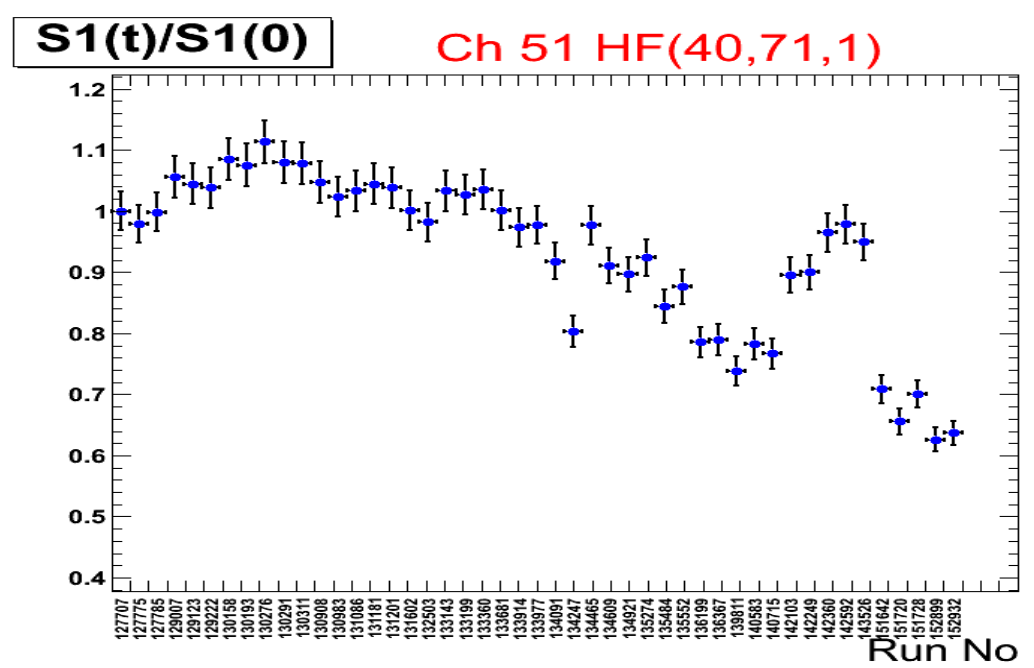

Şekil 11. Sadece bir kanal için, birinci sinyalin bir referans verisine göre tüm verilerdeki davranışını gösteren dağılım.

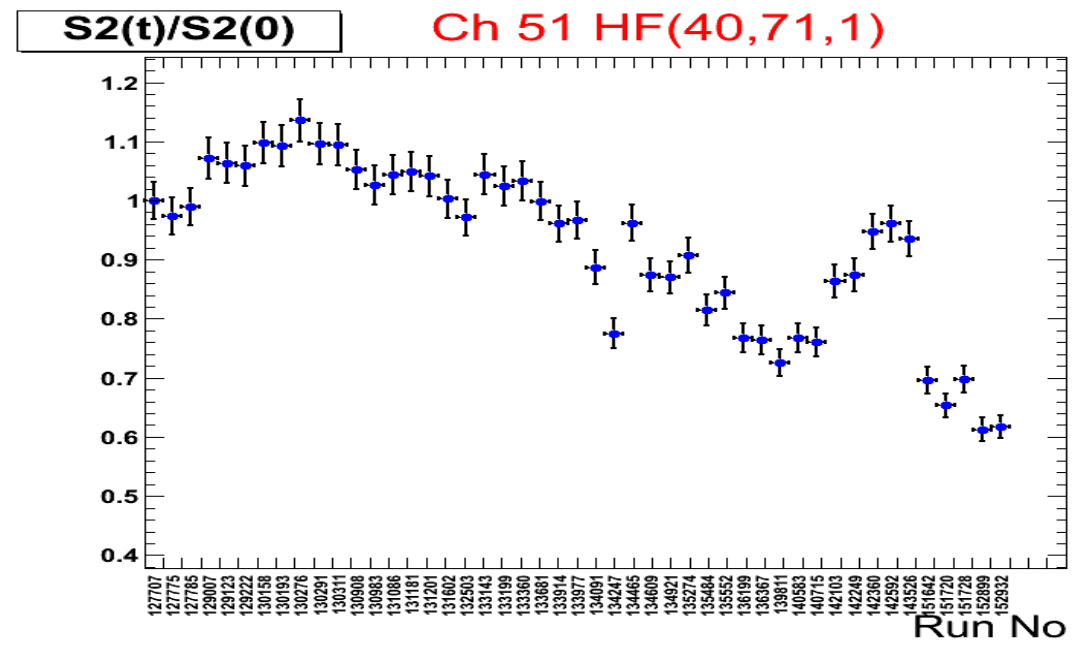

Şekil 12. Sadece bir kanal için, ikinci sinyalin bir referans verisine göre tüm verilerdeki davranışını gösteren dağ 11 im. 
Radyasyondan kaynaklanan hasarı belirlemek için denklem 3'te verilen oran hesaplanarak, zamanın bir fonksiyonu olarak değişimin yönelimi gözlenmiştir. Şekil 13 'te gösterilen dağılımın yönelimi bu kanal için radyasyon hasarı hakkında bilgi vermektedir. Yönelimin zamanla (yeni alınan veri) azalması radyasyon hasarını gösterir. Diğer bütün kanallar için benzeri grafikler elde edilmiştir [20].

$$
R_{t} / R_{0}=\left[S_{2}(t) / S_{1}(t)\right] /\left[S_{2}(0) / S_{1}(0)\right]
$$

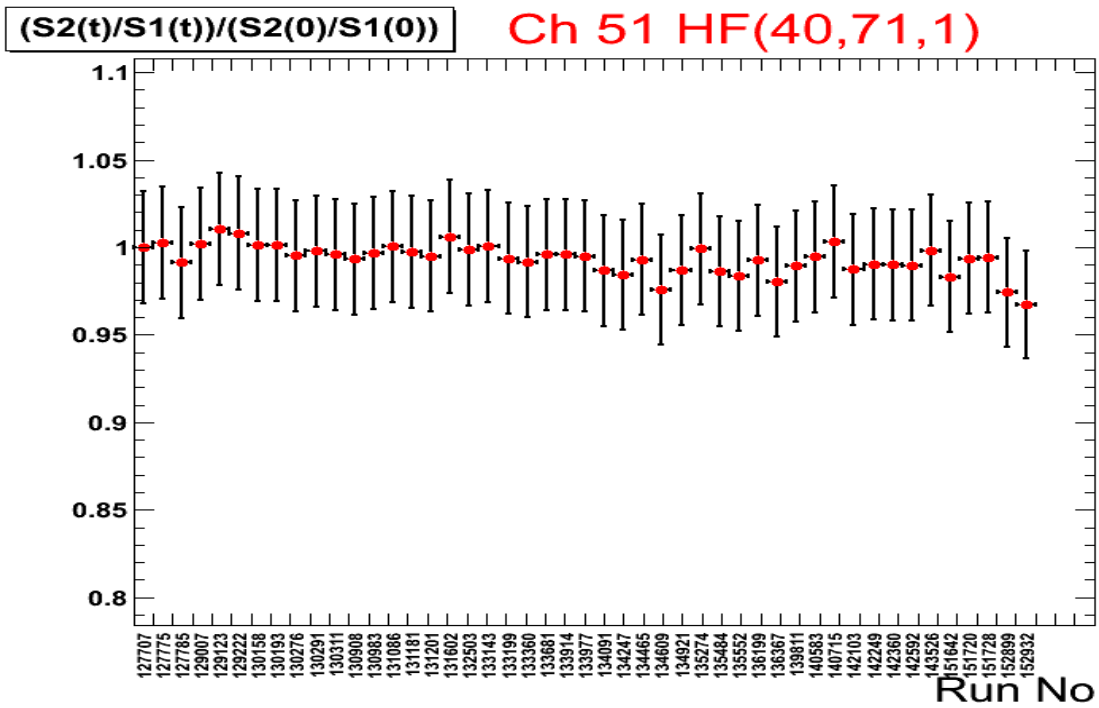

Şekil 13. Sadece bir kanalın radyasyondan etkilenme durumunu tüm veriler üzerinden gösteren dağılım.

\section{Sonuç ve Yorum}

Hadronik kalorimetre, CMS'deki alt sistemlerden biridir. Hadronların enerji ölçümüne ve olayların kayıp dik enerjisinin ölçümüne ayrılmış bir detektördür [21,22]. Hadronik kalorimetreler, parçacık fiziği deneylerinde önemli yer tutarlar. $\mathrm{Bu}$ dedektörleri güvenilir şekilde kullanabilmek için iyi kalibre edilmeleri gerekir. Kalibre etmek için, enerjisi bilinen parçacıklar (radyoaktif kaynaklar) veya LED ve Lazer 1şığı kullanılır [23]. Çeşitli nedenlerle (radyasyona maruz kalma, tuhaf elektronik sinyaller, bireysel kanalların tepkileri, vb.) kanallar gerçeklerden farklı enerji ölçebilirler. Bu ölçülen enerji doğru değildir ve bir miktar düzeltme katsayısına ihtiyaç duyulacaktır. HF, konumu itibariyle CMS alt detektörlerinin en yoğun radyasyona maruz kalan kalorimetresidir. Kuvars fiberlerin ilettiği 1şığın genliği, radyasyon nedeniyle zamanla azalır. Bu durumda enerji kalibrasyonları ve düzeltme katsayıları belirlenerek verinin tekrar yapılandırılması gerekir [24,25].

$\mathrm{Bu}$ çalışmada, CMS'nin ileri bölgesindeki HF kalorimetresinin aktif maddesi olan kuvars fiberlerin radyasyon hasarı, dedektörün çalışma periyodu sırasında alınan lazer verileri analiz edilerek belirlenmiştir. RadDam kanallarından alınan verilerin analizi ile, radyasyon hasarını online olarak izleyen sistem kontrol edilerek analiz yönteminde yenilikler sunulmuştur. HF dedektörünün 8 kama ve 7 kulesine yerleştirilen 56 kanaldan alınan lazer sinyallerinin analizi sonucunda, yeterli veri olmadığ i ç̧in kanallardan sadece birindeki sinyalin düzgün analiz edilememiştir. İki kanalın ise diğer kanallara göre kararsız davranışlar gösterdiği belirlenmiştir. 
2010 y1lı boyunca sistemden alınan 47 lazer veri setleri kullanılarak hem yöntemin geliştirilmesi sağlanmış hem de dedektörde meydana gelen radyasyon hasarının takibi yapılmıştır. Işın demet eksenine yakın olan bölgelerin radyasyon hasarı belirginleşse de 2010 yılı itibariyle detektörde, alınan veride düzeltme faktörü uygulamayı gerektirecek radyasyon hasarı belirlenememiştir.

\section{Araştırmacıların Katkı Oranı Beyanı}

Yalçın Güler: Yazılım, Araştırma, Orijinal Taslak Yazımı, Veri İyileştirme, Görselleştirme, İnceleme ve Düzenleme

\section{Destek ve Teşekkür Beyanı}

Bu çalışma Yalçın GÜLER'in yüksek lisans tezinden türetilmiştir. Tez çalışmamı CERN' de bulunarak tamamlamamı ve yaptığım çalışmaları desteklemelerinden dolayı TAEK'e (Türkiye Atom Enerjisi Kurumu) ve Çukurova Üniversitesi Fizik Bölümü Proje yürütücüsü Prof. Dr. Gülsen Önengüt'e çok teşekkür ederim. Yaptığım çalışmalarımda desteğini, yardımını ve tavsiyelerini daima yanımda bulduğum değerli hocam Prof. Dr. İsa Dumanoğlu'na çok teşekkür ederim.

\section{Çatışma Beyanı}

$\mathrm{Bu}$ çalışmanın yazarları olarak herhangi bir çatışma beyanımız bulunmadığını bildiririz.

\section{Etik Kurul Onayı ve/veya Aydınlatılmış Onam Bilgileri}

Bu çalışmanın yazarları olarak herhangi bir etik kurul onayı ve/veya aydınlatılııs onam bilgileri beyanımız bulunmadığını bildiririz

\section{Kaynakça}

[1] R. Oerter "The Theory of Almost Everything: The Standard Model, the Unsung Triumph of Modern Physics," (Kindle ed.), Penguin Group p. 2. ISBN 0-13-236678-9.

[2] G. Aad, "The ATLAS Experiment at the CERN Large Hadron Collider," J. Instrum., 3(08), S08003, 2008.

[3] K. Aamodt, "The ALICE experiment at the CERN LHC," J. Instrum., 3(08), S08002 2008.

[4] R. Aaij, "LHCb Detector Performance," Int. J. Mod. Phys. 30, 07 1530022, 2015.

[5] S. Chatrchyan, "The CMS experiment at the CERN LHC," JINST 3 S08004, 2008.

[6] G. L. Bayatiyan, "CMS Hadronic Calorimeter Project Technical Design Report,” CERN/LHCC-97-31 1997b.

[7] CMS-HCAL Collaboration, "Design performance and calibration of the CMS forward calorimeter wedges," Eur. Phys. J. C, 53, 139-166, 2008.

[8] The CMS Collaboration, “Technical Proposal,” CERN/LHCC94-39 1994.

[9] The CMS Collaboration, "The Hadron Calorimeter Project Technical Design Report," CERN/LHCC97-31 1997.

[10] B. Bilki and Y. Onel, "Design, Construction and Commissioning of the Upgrade Radiation Damage Monitoring System of the CMS Hadron Forward Calorimeters," 2018 IEEE Nuclear Science Symposium and Medical Imaging Conference Proceedings (NSS/MIC), Sydney, Australia, 2018, pp. 1-4,

[11] A.Penzo and Y. Onel, "The CMS-HF quartz fiber calorimeters," Journal of Physics: Conference Series, 160, 012014, 2009.

[12] A.Ferrando, et al., "A compensating quartz fiber calorimeter for small angle calorimetry at the LHC", Nucl. Instrum. Methods Phys. Res. A, 390(1-2), 63-78, 1997.

[13] U. Akgun and Y. Onel, "Radiation-Hard Quartz Cerenkov Calorimeters", AIP Conference Proceedings of XII International Conference on Calorimetry in High Energy Physics, 2006, pp 282. 
[14] J. P. Merlo and K. Cankocak, "Radiation Hardness Studies of high OH-Content Quartz Fibers Irradiated with $24 \mathrm{GeV}$ Protons," Proceedings of 9th ICATTP Conference, World Scientific, 2006, 838.

[15] N. Akchurin, et al., "Test beam results of CMS quartz fibre calorimeter prototype and simulation of response to high energy hadron jets," Nucl. Instrum. Methods Phys. Res. A, 409(1-3), 593-597, 1998.

[16] P. Gorodetzky, "Quartz fiber calorimetry”, Nucl. Instrum. Methods Phys. Res. A, 361, 1995.

[17] K. Cankocak, "Radiation-hardness measurements of high OH-content quartz fibres irradiated with 24 GeV protons up to 1.25 Grad," Nucl. Instrum. Methods Phys. Res. A, 585, 20-27, 2008.

[18] I. Dumanoglu, et al., "Radiation-hardness studies of high $\mathrm{OH}$ content quartz fibers irradiated with $500 \mathrm{MeV}$ electrons". Nucl. Instrum. Methods Phys. Res. A, 490, 444-455, 2002.

[19] J. Freeman, "Innovations for the CMS HCAL," Fermilab, MS 205, Batavia, IL 60510-500, USA, 2010

[20] Y. GULER, “CMS HF Dedektöründe Kullanılan Fiberlerin Radyasyondan Gördüğü

Zarar1 Görüntüleme Sistemi," Yüksek Lisans Tezi, Fen Billimleri Enstitüsü, Çukurova Üniversitesi, Adana Türkiye, 2011.

[21] The CMS collaboration, "Performance of the CMS missing transverse momentum reconstruction in pp data at $\sqrt{ }_{\mathrm{s}}=8 \mathrm{TeV}, " J$. Instrum., 10(02), P020006, 2015.

[22] The CMS collaboration, "Missing transverse energy performance of the CMS detector," J. Instrum., 6(09), P09001, 2011.

[23] C. W. Fabjan and T. Ludlam, "Calorimetry in High-Energy Physics," Ann. Rev. Nucl. Part. Sci., 32(1), 335-389, 1982.

[24] V. V. Abramov, "Studies of the response of the prototype CMS hadron calorimeter, including magnetic field effects, to pion, electron, and muon beams," Nucl. Instrum. Methods Phys. Res. A, 457(1-2), 75-100, 2001.

[25] E. Hazen, "Radioactive source calibration technique for the CMS hadron calorimeter," Nucl. Instrum. Methods Phys. Res. A, 511(3), 311-327, 2003. 